\title{
Incidence and clinical value of prolonged I-V interval in NICU infants after failing neonatal hearing screening
}

\author{
S. Coenraad $\cdot$ L. J. Hoeve $\cdot$ A. Goedegebure
}

Received: 21 May 2010/Accepted: 22 October 2010/Published online: 11 November 2010

(C) The Author(s) 2010. This article is published with open access at Springerlink.com

\begin{abstract}
Infants admitted to neonatal intensive care units (NICUs) have a higher incidence of perinatal complications and delayed maturational processes. Parameters of the auditory brainstem response (ABR) were analyzed to study the prevalence of delayed auditory maturation or neural pathology. The prevalence of prolonged I-V interval as a measure of delayed maturation and the correlation with ABR thresholds were investigated. All infants admitted to the NICU Sophia Children's Hospital between 2004 and 2009 who had been referred for ABR measurement after failing neonatal hearing screening with automated auditory brainstem response (AABR) were included. The ABR parameters were retrospectively analyzed. Between 2004 and 2009, 103 infants were included: 46 girls and 57 boys. In 58.3\% (60 infants) of our population, the I-V interval was recordable in at least one ear at first diagnostic ABR measurement. In $4.9 \%$, the I-V interval was severely prolonged. The median ABR threshold of infants with a normal or mildly prolonged I-V interval was $50 \mathrm{~dB}$. The median ABR threshold of infants with a severely prolonged I-V interval was $30 \mathrm{~dB}$. In conclusion, in case both peak $\mathrm{I}$ and $\mathrm{V}$ were measurable, we found only a limited (4.9\%) incidence of severely prolonged I-V interval $(\geq 0.8 \mathrm{~ms})$ in this high-risk NICU population. A mild delay in maturation is a more probable explanation than major audiologic or neural pathology, as ABR thresholds were near normal in these infants.
\end{abstract}

S. Coenraad $(\varangle) \cdot$ L. J. Hoeve · A. Goedegebure

Department of Otorhinolaryngology,

Sophia Children's Hospital, Erasmus Medical Center,

Dr. Molewaterplein 60, SP-1455,

3015 GJ Rotterdam, The Netherlands

e-mail: s.coenraad@erasmusmc.nl
Keywords Auditory brainstem response - NICU . Infants · Auditory maturation

\section{Introduction}

Infants admitted to the neonatal intensive care unit (NICU) have a higher incidence of congenital hearing loss as compared to the healthy newborn population $[1,2]$. Several risk factors have been associated with this increased risk [3-6]. Moreover, preterm infants often have a delayed maturation of the auditory system as compared to term infants. This results in a vulnerable population regarding audiologic problems.

The I-V interval is often used as a measure of auditory maturation to describe the central conduction time. It is reported to be increased in preterm infants as compared to term infants [7-9]. The I-V interval shows an age-dependent decline up to about 2 years of age [10-12]. Explanations for the normalization of the I-V interval are increased myelination or increased synaptic efficacy $[8,10,12-15]$. Although it is known that infants admitted to NICUs are at higher risk of developing perinatal complications and abnormal maturational processes, the incidence of prolonged I-V interval in NICU infants who failed neonatal hearing screening is unknown.

What this study adds is the incidence of prolonged I-V interval in a large cohort of NICU infants after failing neonatal hearing screening. We also investigated whether there is a correlation between prolonged I-V interval and elevated auditory brainstem response (ABR) thresholds. The development of these parameters over time was followed to study the auditory maturational changes. 


\section{Patients and methods}

\section{Patients}

The Sophia Children's Hospital is a tertiary care center in Rotterdam, the Netherlands. In 2008, the life birth number in the Netherlands was 184,634, of which 4,003 infants required NICU care of which 639 were admitted to the NICU at Sophia's Children Hospital.

In the Netherlands, all infants admitted to the NICU longer than $24 \mathrm{~h}$ undergo standard hearing screening by means of automated auditory brainstem responses (AABR). The first AABR screening is usually conducted upon discharge from the NICU. In case of unilateral or bilateral failure on AABR screening, AABR measurement should be repeated before 6 weeks corrected age (46 weeks post-conceptional age). Upon second AABR failure children are referred for audiologic evaluation. This audiologic evaluation consists of ABR, transient evoked otoacoustic emissions (TEOAEs) and tympanometry measurement. After diagnostic evaluation, all infants are seen by an experienced audiologist and otorhinolaryngologist. This should ideally take place before 3 months corrected age (52 weeks post-conceptional age).

Between 2004 and 2009, 3,366 infants were admitted to our NICU, of which 3,316 were screened with AABR. A total of 103 infants were referred for ABR analysis after repeated failure on AABR screening. Data of these ABR recordings were used to retrospectively analyze the ABR parameters.

Apparatus and procedures

All children were discharged from the NICU by the time ABR measurement was conducted. ABR measurements were recorded at our outpatient clinic in a soundproof room.

All children were in natural sleep or in calm conditions throughout the assessment. Both ears were sequentially tested. ABRs were recorded using the EUPHRA-1 system using a Toennies preamplifier. Responses were recorded using silver cup electrodes placed at both mastoids with a reference at the vertex and a ground electrode on the forehead. A band-filter was used with cut-off frequencies of $20 \mathrm{~Hz}$ and $3 \mathrm{kHz}$. The repetition frequency was $23 \mathrm{~Hz}$. Click stimuli were presented starting at a level of $90 \mathrm{~dB}$ nHL. With step sizes of $10 \mathrm{~dB}$, the level was decreased until no response was found.

TEOAE measurements were performed using the Otodynamics ILO 288 USB II system with the standard settings. The stimulus level was set to $84 \mathrm{~dB}$ SPL, a number of 260 averages was used.
Tympanometry was performed with an Interacoustics AT $235 \mathrm{H}$ system using the standard settings and a $1 \mathrm{kHz}$ probe frequency. Clinical experts interpreted the results.

After diagnostic evaluation, all infants were seen at the outpatient clinic by an experienced audiologist and otorhinolaryngologist.

Analysis of response

The absolute latencies and interpeak intervals as well as the response thresholds were recorded. Experienced clinical specialists interpreted the ABR waves. The response latencies in milliseconds were obtained by establishing the peak of the wave and reading out the digitally displayed time. The I-V interval was obtained by subtracting the latency of peak I from peak V, measured at $90 \mathrm{~dB}$ nHL stimulation level. The response threshold was estimated by the lowest level at which a response was found. The corresponding hearing loss was estimated as $10 \mathrm{~dB}$ below this level.

The absolute latencies and interpeak intervals of ABR measurement were compared with the references values based on the normal hearing infants from our clinic [16]. These reference values are corrected for post-conceptional age to account for maturational changes in ABR parameters.

TEOAE and tympanometry measurement were used to confirm the diagnosis of conductive hearing loss when available.

\section{Results}

Between 2004 and 2009, 3,366 infants were admitted to our NICU, of which 3,316 were screened with AABR. A total of 103 infants were referred for $\mathrm{ABR}$ analysis after second failure on AABR screening: 46 girls and 57 boys. The median gestational age at birth was 34.7 weeks (interquartile range 27.3-39.3 weeks). The median birth weight was $1,930 \mathrm{~g}$ (interquartile range 946-2,911 g). The median post-conceptional age at first diagnostic ABR measurement was 43 weeks (interquartile range 39-48 weeks). Data of repeated ABR measurement was available for 79 of the 103 infants $(76.7 \%)$. The majority $(75 \%)$ of infants that had no repeated $A B R$ measurement had a normal $A B R$ results at primary assessment. Five infants died after primary ABR measurement. The median post-conceptional age at final ABR measurement was 83 weeks (interquartile range 62-124 weeks).

ABR results were analyzed in 103 NICU infants (206 ears). In Table 1, the different types of responses at first ABR measurement are presented. In some cases, all peaks were recordable, whereas in others only a single peak 
Table 1 The recordable ABR peaks of infants referred for $A B R$ analysis after failing AABR neonatal hearing screening are presented

\begin{tabular}{lc}
\hline Recordable ABR peaks & Number of infants \\
\hline Peaks I, V & 60 \\
Peak I & 1 \\
Peak V & 19 \\
No response & 23 \\
\hline
\end{tabular}

The peaks were recordable in at least one ear, but were not always symmetrically measurable. All infants with no measurable response were affected on both sides

(mostly peak V) or no measurable ABR response was found. The peaks were not always equally measurable in both ears.

In 104 ears (60 infants), the I-V interval was measurable at the first diagnostic ABR after failing neonatal hearing screening. Figure 1 shows the I-V intervals of these infants and the age corrected reference values used in our clinic [16]. A clear age-dependent decline of I-V interval with increasing post-conceptional age is present. A prolonged $\mathrm{I}-\mathrm{V}$ interval compared with our reference values is mainly seen in the younger post-conceptional ages.

Further on we will focus on infants instead of ears. In 44 infants, the $\mathrm{I}-\mathrm{V}$ interval was recordable in both ears. In eight infants, the $\mathrm{I}-\mathrm{V}$ interval was recordable only in the right ear and in another eight infants, the I-V interval was recordable only in the left ear. Table 2 shows the number of cases in which the I-V interval was prolonged by one (mildly) or two (severely) standard deviations compared to our reference values. In $15.5 \%$ of our population (16 infants) at least a mildly prolonged I-V Interval was found, in $4.9 \%$ of our population ( 5 infants), the I-V interval was severely prolonged by two standard deviations. It can be concluded from Table 2 that a prolonged I-V interval very often only affects one ear.

Table 3 shows the follow-up of the 16 infants with a prolonged I-V interval. Nineteen percent of infants with a prolonged I-V interval, by either one or two standard deviations, developed a normal $\mathrm{I}-\mathrm{V}$ interval after followup.

\section{ABR response thresholds}

To give a better view on the effect of a prolonged I-V interval on the ABR results, we also analyzed the corresponding ABR thresholds. In infants with a normal I-V interval, the median ABR threshold was $50 \mathrm{~dB}$ (interquartile range $32.4-70 \mathrm{~dB}$ ). In infants with a mildly prolonged I-V interval (by one standard deviation), the median ABR threshold was $50 \mathrm{~dB}$ (interquartile range 37.5-70 dB). In infants with a severely prolonged I-V

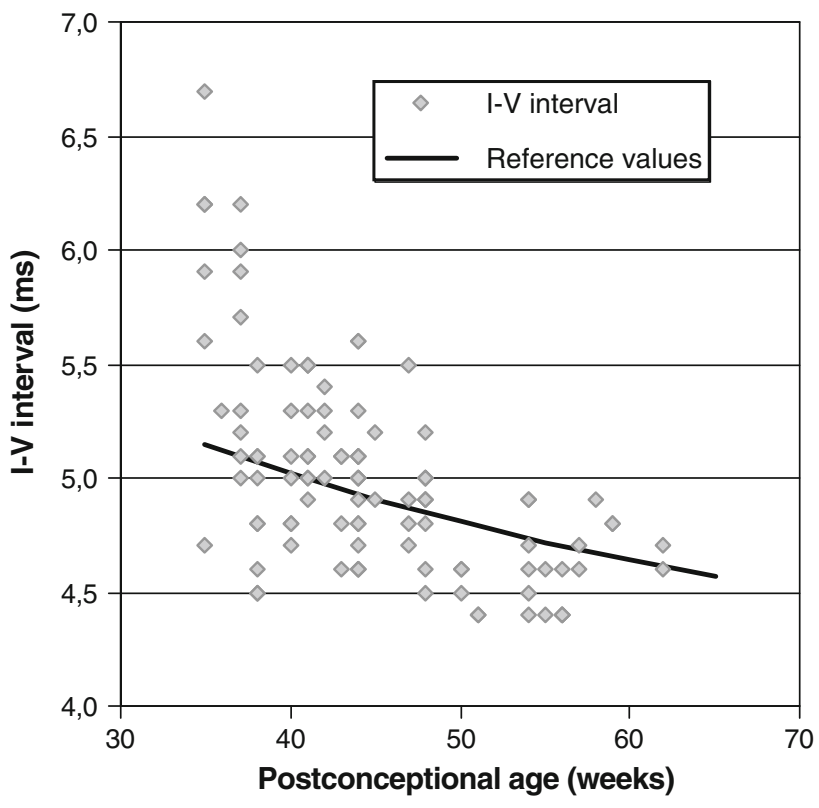

Fig. 1 The I-V interval of 104 ears (60 infants) with recordable I-V interval at first diagnostic ABR measurement after failing neonatal hearing screening is presented. The black line represents the reference values used in our clinic that correct for post-conceptional age

Table 2 The number of infants in which the I-V interval is mildly prolonged [by one standard deviation $(\geq 0.4 \mathrm{~ms} ;<0.8 \mathrm{~ms})$ ] or severely prolonged [by two standard deviations $(\geq 0.8 \mathrm{~ms})$ ] are presented

\begin{tabular}{lll}
\hline & $\begin{array}{l}\text { I-V interval } \\
\text { mildly prolonged } \\
(\geq 0.4 \mathrm{~ms} ;<0.8 \mathrm{~ms})\end{array}$ & $\begin{array}{l}\text { I-V interval } \\
\text { severely prolonged } \\
(\geq 0.8 \mathrm{~ms})\end{array}$ \\
\hline Both ears & 1 & $3^{\mathrm{a}}$ \\
Right ear & 3 & 1 \\
Left ear & 7 & 1 \\
Total & 11 & 5
\end{tabular}

a One infant had a mildly prolonged I-V interval $(\geq 0.4 \mathrm{~ms} ;<0.8 \mathrm{~ms})$ in the left ear and a severely prolonged I-V interval $(\geq 0.8 \mathrm{~ms})$ in the right ear and has been classified in the severely prolonged group based on the worst ear

interval (by two standard deviations), the median $\mathrm{ABR}$ threshold was $30 \mathrm{~dB}$ (interquartile range 30-35 dB).

After follow-up, the median ABR threshold of infants with a normal $\mathrm{I}-\mathrm{V}$ interval was $50 \mathrm{~dB}$ (interquartile range 30-62.5 dB). The median ABR threshold of infants with a prolonged I-V interval after follow-up was also $50 \mathrm{~dB}$ (interquartile range 30-60 dB).

In $31.5 \%$ of infants with elevated ABR thresholds ( $\geq 50 \mathrm{~dB}$ ), a flat tympanogram was found, it should be noted that tympanometry was not available in all infants. A conductive hearing loss will influence ABR thresholds and peak latencies, but will have no effect on the I-V interval latency. 
Table 3 Follow-up of infants with a prolonged I-V interval (by either one or two standard deviations) at primary ABR assessment

Final ABR result

Total number of infants with a prolonged $\mathrm{I}-\mathrm{V}$ interval $(\%)$

I-V interval becomes normal

$3(19)$

I-V interval remains prolonged ( $\geq 0.4 \mathrm{~ms})$

$7(50)$

$\mathrm{I}-\mathrm{V}$ interval is not recordable

$1(6)$

Not repeated

$5(25)$

\section{Discussion}

The prevalence of prolonged I-V interval and the correlation with ABR thresholds in a population of 103 NICU infants who failed neonatal hearing screening was analyzed. In $58.3 \%$ of infants, the I-V interval was recordable at first diagnostic ABR measurement after failing neonatal hearing screening. A prolongation of the $\mathrm{I}-\mathrm{V}$ interval by one or two standard deviations $(\geq 0.4 \mathrm{~ms}$ ) was found in $15.5 \%$ of our population.

Jiang et al. [7] found an incidence of abnormal central ABR component in $17 \%$ of preterm very low birth weight infants. Although the populations differ with respect to birth weight and failing neonatal hearing screening, the prevalence of prolonged $\mathrm{I}-\mathrm{V}$ interval as a measure of abnormal central component concur. It is known that highrisk infants have an increased incidence of prolonged I-V interval as compared to low risk infants [17].

Several studies regarding normal values and maturational changes of ABR parameters have reported no significant differences between right and left ears [8, 18, 19]. Therefore, it is remarkable that we found that a prolonged I-V interval often only affects one ear. However, in the three infants with a unilateral prolonged $\mathrm{I}-\mathrm{V}$ interval by two standard deviations, the I-V interval in the other ear was either unrecordable or prolonged by one standard deviation. Therefore, no large inter aural differences in I-V interval were found.

Jiang et al. [7] found that $14 \%$ had an elevation of ABR threshold $(>30 \mathrm{~dB})$. In our population, the median $\mathrm{ABR}$ threshold was elevated at $50 \mathrm{~dB}$ for both infants with a normal I-V interval and infants with a mildly prolonged I-V interval. The ABR threshold of infants with a severely prolonged $\mathrm{I}-\mathrm{V}$ interval was lower, median ABR threshold $30 \mathrm{~dB}$. The lower ABR thresholds in infants with more severe prolongation of $\mathrm{I}-\mathrm{V}$ interval suggest that a severely prolonged I-V interval has no large impact on hearing sensitivity. This also suggests that a delay in maturation is a more probable cause than major audiologic or neural pathology. This is supported by the fact that these infants are among the younger infants in our population.
The immature auditory system is characterized by increased ABR peak latencies and increased ABR thresholds. We know that auditory maturation can be delayed in preterm as compared to term infants [17]. The maturation effect of the response threshold is relatively small and matures sooner than the maturation of the I-V interval [20]. Therefore, the combination of a normal response threshold and a prolonged I-V interval is likely to occur in case of delayed auditory maturation. In addition, in the presence of a normal ABR threshold, severe neural pathology is unlikely.

In $41.7 \%$ of the population, the I-V could not be recorded at first diagnostic ABR measurement. In 22.3\%, no measurable ABR response was found. After follow-up, this improved to normal or prolonged I-V interval for eight infants (7.8\% of the total population). In these infants again delayed auditory maturation or dissolving of middle ear effusion is the most likely explanation. There were only a few infants in whom a normal I-V interval deteriorated to a prolonged or absent I-V interval after repeated ABR measurement.

The aim of universal neonatal hearing screening is to diagnose hearing impairment and start treatment before the age of 6 months [2]. Based on our findings that only $4.9 \%$ of infants have a prolonged I-V interval, the timing of the first diagnostic evaluation in our population seems adequate (median post-conceptional age 43 weeks). When a prolonged I-V interval is found, infants should be followed to determine if the I-V interval normalizes. Especially since we know that the maturational processes can be delayed in preterm infants.

\section{Conclusion}

I-V interval and ABR thresholds in a population of 103 NICU infants who failed neonatal hearing screening were analyzed. In $58.3 \%$ of the population I-V could be measured at primary ABR measurement. In $4.9 \%$ of the population a severely prolonged I-V interval was found. Corresponding ABR thresholds were lower as compared to infants with normal I-V interval, suggesting delayed auditory maturation or at least no large impact on hearing pathology.

Acknowledgments No sources of support.

Conflict of interest No conflict of interest.

Open Access This article is distributed under the terms of the Creative Commons Attribution Noncommercial License which permits any noncommercial use, distribution, and reproduction in any medium, provided the original author(s) and source are credited.

\section{References}

1. Vohr BR, Widen JE, Cone-Wesson B, Sininger YS, Gorga MP, Folsom RC et al (2000) Identification of neonatal hearing 
impairment: characteristics of infants in the neonatal intensive care unit and well-baby nursery. Ear Hear 21(5):373-382

2. American Academy of Pediatrics JCoIH Position Statement (2007) Principles and guidelines for early hearing detection and intervention programs. Pediatrics 120(4):898-921

3. Declau F, Boudewyns A, Van den Ende J, Peeters A, van den Heyning P (2008) Etiologic and audiologic evaluations after universal neonatal hearing screening: analysis of 170 referred neonates. Pediatrics 121(6):1119-1126

4. Hille ET, van Straaten HI, Verkerk PH (2007) Prevalence and independent risk factors for hearing loss in NICU infants. Acta Paediatr 96(8):1155-1158

5. Robertson CM, Howarth TM, Bork DL, Dinu IA (2009) Permanent bilateral sensory and neural hearing loss of children after neonatal intensive care because of extreme prematurity: a thirtyyear study. Pediatrics 123(5):e797-e807

6. Uus K, Bamford J (2006) Effectiveness of population-based newborn hearing screening in England: ages of interventions and profile of cases. Pediatrics 117(5):e887-e893

7. Jiang ZD, Brosi DM, Wilkinson AR (2001) Hearing impairment in preterm very low birthweight babies detected at term by brainstem auditory evoked responses. Acta Paediatr 90(12):14111415

8. Sleifer P, da Costa SS, Coser PL, Goldani MZ, Dornelles C, Weiss K (2007) Auditory brainstem response in premature and full-term children. Int J Pediatr Otorhinolaryngol 71(9): 1449-1456

9. Pasman JW, Rotteveel JJ, de Graaf R, Maassen B, Visco YM (1996) The effects of early and late preterm birth on brainstem and middle-latency auditory evoked responses in children with normal neurodevelopment. J Clin Neurophysiol 13(3):234-241

10. Eggermont JJ, Salamy A (1988) Development of ABR parameters in a preterm and a term born population. Ear Hear 9(5):283-289

11. Gorga MP, Kaminski JR, Beauchaine KL, Jesteadt W, Neely ST (1989) Auditory brainstem responses from children three months to three years of age: normal patterns of response. II. J Speech Hear Res 32(2):281-288

12. Mochizuki Y, Go T, Ohkubo H, Motomura T (1983) Development of human brainstem auditory evoked potentials and gender differences from infants to young adults. Prog Neurobiol 20(3-4):273-285

13. Ponton CW, Moore JK, Eggermont JJ (1996) Auditory brain stem response generation by parallel pathways: differential maturation of axonal conduction time and synaptic transmission. Ear Hear $17(5): 402-410$

14. Moore JK, Ponton CW, Eggermont JJ, Wu BJ, Huang JQ (1996) Perinatal maturation of the auditory brain stem response: changes in path length and conduction velocity. Ear Hear 17(5):411-418

15. Issa A, Ross HF (1995) An improved procedure for assessing ABR latency in young subjects based on a new normative data set. Int J Pediatr Otorhinolaryngol 32(1):35-47

16. Coenraad S, van Immerzeel T, Hoeve LJ, Goedegebure A (2010) Fitting model of ABR age dependency in a clinical population of normal hearing children. Eur Arch Otorhinolaryngol 267(10):1531-1537

17. Jiang ZD, Brosi DM, Li ZH, Chen C, Wilkinson AR (2005) Brainstem auditory function at term in preterm babies with and without perinatal complications. Pediatr Res 58(6):1164-1169

18. Gorga MP, Reiland JK, Beauchaine KA, Worthington DW, Jesteadt W (1987) Auditory brainstem responses from graduates of an intensive care nursery: normal patterns of response. J Speech Hear Res 30(3):311-318

19. Rotteveel JJ, de Graaf R, Colon EJ, Stegeman DF, Visco YM (1987) The maturation of the central auditory conduction in preterm infants until three months post term. II The auditory brainstem responses (ABRs). Hear Res 26(1):21-35

20. Sininger YS, Abdala C (1996) Hearing threshold as measured by auditory brain stem response in human neonates. Ear Hear 17(5):395-401 